\title{
An Updated TRMM Composite Climatology of Tropical Rainfall and Its Validation
}

\author{
JIAN-JIAN WANG AND ROBERT F. ADLER \\ Earth System Science Interdisciplinary Center, University of Maryland, College Park, College Park, Maryland \\ GEORGE J. HufFMAN \\ Laboratory for Atmospheres, NASA Goddard Space Flight Center, Greenbelt, Maryland \\ DAVID BOLVIN \\ Science Systems and Applications, Inc., Greenbelt, Maryland
}

(Manuscript received 14 June 2013, in final form 20 August 2013)

\begin{abstract}
An updated 15-yr Tropical Rainfall Measuring Mission (TRMM) composite climatology (TCC) is presented and evaluated. This climatology is based on a combination of individual rainfall estimates made with data from the primary TRMM instruments: the TRMM Microwave Imager (TMI) and the precipitation radar (PR). This combination climatology of passive microwave retrievals, radar-based retrievals, and an algorithm using both instruments simultaneously provides a consensus TRMM-based estimate of mean precipitation. The dispersion of the three estimates, as indicated by the standard deviation $\sigma$ among the estimates, is presented as a measure of confidence in the final estimate and as an estimate of the uncertainty thereof. The procedures utilized by the compositing technique, including adjustments and quality-control measures, are described. The results give a mean value of the TCC of $4.3 \mathrm{~mm} \mathrm{day}^{-1}$ for the deep tropical ocean beltbetween $10^{\circ} \mathrm{N}$ and $10^{\circ} \mathrm{S}$, with lower values outside that band. In general, the TCC values confirm ocean estimates from the Global Precipitation Climatology Project (GPCP) analysis, which is based on passive microwave results adjusted for sampling by infrared-based estimates. The pattern of uncertainty estimates shown by $\sigma$ is seen to be useful to indicate variations in confidence. Examples include differences between the eastern and western portions of the Pacific Ocean and high values in coastal and mountainous areas. Comparison of the TCC values (and the input products) to gauge analyses over land indicates the value of the radar-based estimates (small biases) and the limitations of the passive microwave algorithm (relatively large biases). Comparison with surface gauge information from western Pacific Ocean atolls shows a negative bias $(\sim 16 \%)$ for all the TRMM products, although the representativeness of the atoll gauges of open-ocean rainfall is still in question.
\end{abstract}

\section{Introduction}

The first-time use of both active and passive microwave instruments on board the Tropical Rainfall Measuring Mission (TRMM, launched in late 1997) has made TRMM the foremost satellite for the study of precipitation in the tropics. One of the key goals of TRMM has been to define the spatial and seasonal climatological rainfall in the tropics as accurately as possible in order to quantify

Corresponding author address: Dr. Jian-Jian Wang, Earth System Science Interdisciplinary Center, University of Maryland, College Park, 5825 University of Maryland Research Park, College Park, MD 20740.

E-mail: jjwang@umd.edu this key component of the hydrological cycle. TRMM's instrument complement, its precessing orbit sampling the diurnal cycle, and its 15-yr lifetime make it nearly ideal for producing such a tropical rainfall climatology.

The TRMM surface rainfall retrievals from the multiple instruments and algorithms are converging to become the standard for improving long-term climatologies and for comparison with climate models. There is no doubt that having multiple retrievals of precipitation from different instruments using different types of observations has been one of the biggest advantages of TRMM. TRMM precipitation estimates include those based on the passive microwave instrument [TRMM Microwave Imager (TMI)], those based on the precipitation radar (PR), and an estimate based on an algorithm that uses a direct combination

DOI: 10.1175/JCLI-D-13-00331.1 
of information from both sensors. There is also a heavily used multisatellite estimate that uses TRMM data to calibrate rain estimates from other satellites to produce a TRMM Multisatellite Precipitation Analysis (TMPA; Huffman et al. 2007). Differences among these estimates found by scientists (e.g., Berg et al. 2006; Masunaga and Kummerow 2005; Shige et al. 2008) have led to a better understanding of the underlying physics and the validity of assumptions in the various retrieval techniques. However, having multiple estimates for the rainfall, even for climatological rainfall, has also led to confusion and, to some degree, a lack of use of the mean values from the multiple TRMM estimates.

To reach a consensus from TRMM and to have a summary of TRMM rainfall products as a ready comparison with other non-TRMM estimates and for comparison with simulated precipitation from general circulation models, Adler et al. (2009) utilized the multiple estimates based on TRMM data and the various TRMM standard products (Kummerow et al. 2000) to generate a 10-yr (1998-2007) TRMM, version 6 (V6), based composite climatology of tropical rainfall, the TRMM composite climatology (TCC). The TCC from the 2009 paper, hereafter referred to as TCC (2009), used selected TRMM V6 products, included quality control to eliminate artifacts, and accounted for the effects of the orbit altitude boost in 2001 based on a statistical technique (Wang et al. 2008). TCC (2009) also used the variation among the estimates as a measure of error or an indicator of degree of confidence in the mean value.

The purpose of this paper is to update the TCC with version 7 (V7) of the TRMM data products that go into the TCC, to change the list of input products to restrict it to those that only use data from the TRMM satellite itself, to improve the orbit boost adjustment for the PR product, to improve the quality-control procedures, and, of course, to extend the data record to 15 years. The monthly and annual climatologies and associated error estimates are then available for further analysis by users.

This paper will include two major areas of focus: (i) describing the construction of the updated 15-yr (19982012) TCC tropical rainfall climatology using the methodology similar to that described by Adler et al. (2009), but with some modifications; and (ii) validating and evaluating the new TCC, including comparisons with the Global Precipitation Climatology Project (GPCP) monthly rainfall product (Adler et al. 2003). Various rain gauge datasets and analyses will be used for comparison and validation, including the Global Precipitation Climatology Centre (GPCC) full data reanalysis (version 6) (Schneider et al. 2011), with additional attention paid to the southeastern United States and southeastern China, where dense and reliable rain gauge networks exist, and with the comprehensive Pacific Rainfall Database (PACRAIN) atoll rain gauge data over the central and western Pacific. The comparison against the ground-based GPCC and PACRAIN will be done for the 13-yr (1998-2010) period as a result of the availability of those datasets. We will also examine the utility of using the dispersion of the input products as a guide or measure of uncertainty or confidence.

\section{Data and methodology to construct composite climatology}

TRMM rainfall estimates include the standard products from single instruments: a combined instrument retrieval and a multisatellite analysis over the TRMM domain. For this new version of the TCC using data from TRMM V7, there have been some changes in the input datasets and in the methods. For the previous TCC V6 product (Adler et al. 2009), over the ocean, the TCC inputs include the passive microwave retrieval using data from the TMI product 2A12 (Kummerow et al. 2001), the active microwave retrieval using data from the PR product 2A25 (Iguchi and Meneghini 1994), and the TMI-PR combined product, a separate retrieval using different assumptions (2B31; Haddad et al. 1997). Over land, the TMI V6 estimates were known to overestimate surface rainfall (e.g., Masunaga et al. 2002), especially in the warm season. Therefore, the TMI product $2 \mathrm{~A} 12$ was not used over land in TCC (2009). To include information from passive microwave retrievals while excluding known significant biases, the TRMM Multisatellite Precipitation Analysis product 3B43 (Huffman et al. 2007), which uses passive microwave retrievals from many satellites, adjusted by the TM-PR combined product $2 \mathrm{~B} 31$ and with a final adjustment and merger using rain gauge information over land, was used as a replacement.

In the TRMM V7 products, the TMI land rainfall algorithm has two major improvements (Gopalan et al. 2010). The relations between rain rates and TMI $85-\mathrm{GHz}$ brightness temperatures $T_{b}$ for convective and stratiform rain are generated using collocated TMI and PR data. In addition, estimation of the convective-tototal ratio of rainfall is modified to significantly lower the overestimation by TMI in warm season. From our recent analysis of the TRMM V7 products, it is confirmed that TMI rainfall estimates over land have lower values and somewhat better agreement with the PR and the combined TMI-PR products in most regions, although artifacts exist in mountainous and other regions because of the problematic rainfall screening processes in the algorithm. Unfortunately, there are still significant biases in the TMI-based retrievals as will be shown later in this paper. However, we decided to include the TMI V7 estimates over land instead of the TMPA as one of the components in the TCC V7 over land using some 
quality-control techniques. Consequently, when using TMI, PR, and TMI-PR combined products as the inputs of TCC over both ocean and land, the new version of the TCC becomes a TRMM-satellite-only rainfall climatology for the TRMM era and includes no rain gauge information.

Rain-rate estimates from the PR product $2 \mathrm{~A} 25$ retrievals are available at various heights, including the estimated surface (ES), the near surface (NS), and at various altitudes. For the previous TCC (2009) and this new climatology the NS estimates are chosen because this estimate is the lowest level where the radar return itself is the dominant input. In general, the NS estimates are slightly larger than the ES retrievals because of the shape of the assumed reflectivity profiles used. In addition, the PR retrievals were impacted by the satellite orbit boost from 350 to $402 \mathrm{~km}$ in August 2001. A thorough evaluation of boost effects on PR rainfall estimates by Shimizu et al. (2009) concluded that the orbit boost caused a 5.4\% rainfall decrease at the near-surfacelevel mean rain rates, which should be adjusted for in the postboost period. We have used that adjustment factor over both ocean and land for the new TCC, in place of the $6.0 \%$ factor used in the TCC (2009).

The TCC is calculated at a spatial resolution of $0.5^{\circ}$, covering the latitude band from $36^{\circ} \mathrm{S}$ to $36^{\circ} \mathrm{N}$. We first calculate the month-of-the-year climatologies for all four TRMM products including TMI, PR, TMI-PR combined, and TMPA based on $15 \mathrm{yr}$ (1998-2012) of TRMM data. Although the TMPA product is not used directly in the TCC, it plays a role in the data quality-control process as a reference.

The TMI-based retrievals are known to have significant problems with regard to rain/no rain screening (Wang et al. 2009) that may lead to misidentification of surface snow, wet/cold ground, and certain desert areas as rainfall, creating obvious rainfall artifacts in some mountainous and semiarid regions. Even if these misidentifications happen only relatively occasionally, they result in artificial rain maxima when totaled over a month or climatology. To screen out those unreasonable monthof-the-year TMI values over land due to the problems discussed before, an automated quality-control scheme was implemented. The TMI month-of-the-year data are excluded from the construction of the month-of-the-year TCC if one of the criteria below is met:

1) TMI rainfall is $50 \%$ more than the average of PR, PR-TMI combined, and TMPA rainfall; and TMI rainfall is more than $1 \mathrm{~mm}$ day $^{-1}$.

2) TMI rainfall is $50 \%$ less than the average of PR, PRTMI combined, and TMPA rainfall; and the average rainfall of other three products is more than $1 \mathrm{~mm}^{\text {day }}{ }^{-1}$.
The application of this quality-control procedure eliminates about $16 \%$ of TMI results over land. Monthly PR and TMI-PR combined data are also carefully examined to remove some apparent artifacts using the techniques described by Adler et al. (2009). The extreme numbers in the PR and TMI-PR combined datasets are removed as artifacts when they meet the following two criteria:

1) In one year, the value of the monthly rainfall at a certain point is at least 5 times higher than the 10 -yr average. The eliminated points are usually at least 10 times higher than the average of the remaining nine years.

2) The value of the monthly rainfall at that point is also at least 5 times larger than the values from TMI.

Next, the quality-controlled 15-yr rainfall estimates from TMI, PR, and TMI-PR combined products are averaged to construct the month-of-the-year TCC rainfall estimate at each grid location. Where the TMI-based estimates have been eliminated (16\% of grids over land), the remaining two products are averaged. The mean of the month-of-the-year TCC precipitation becomes the TCC annual rainfall climatology.

\section{Results}

The new 15-yr TCC map and the map of the standard deviation among the three products are shown in Fig. 1. The major tropical precipitation patterns and features are clearly demonstrated. Over the ocean, the narrow and intense intertropical convergence zone (ITCZ) across the Pacific Ocean around $5^{\circ}-10^{\circ} \mathrm{N}$, and the broader but weaker Atlantic ITCZ are both clearly present. The South Pacific convergence zone (SPCZ) extends southeastward from the Maritime Continent toward midlatitudes. Over the land, the maxima in rainfall over the Maritime Continent, tropical Africa, and South America are evident. In addition, localized rainfall maxima associated with orographic effects (e.g., along the southern flank of the Himalaya, the windward side of the Ghats Mountains, and the west coast of the Andes) are also apparent. The rainiest point over the ocean is in the extreme eastern Pacific Ocean along the ITCZ, just off the South American coast $\left(19.2 \mathrm{~mm} \mathrm{day}^{-1}\right)$. Farther to the west, a relative maximum of $10.1 \mathrm{~mm}^{-1}{ }^{-1}$ occurs in the central Pacific Ocean (part of the ITCZ at $7.75^{\circ} \mathrm{N}, 139.0^{\circ} \mathrm{W}$ ) while another relative maximum of $10.4 \mathrm{~mm}$ day $^{-1}$ occurs in the western Pacific Ocean (part of the ITCZ at $4.75^{\circ} \mathrm{N}, 158.5^{\circ} \mathrm{E}$ ). Other ocean peaks are $11.9 \mathrm{mmday}^{-1}$ over the SPCZ and a smaller maximum value of $8.8 \mathrm{~mm}$ day $^{-1}$ in the Atlantic ITCZ. Over land, the peak values are $13.3 \mathrm{~mm} \mathrm{day}^{-1}$ in the Maritime Continent and $12.4 \mathrm{~mm}_{\text {day }}{ }^{-1}$ in the coastal region of Andes. 

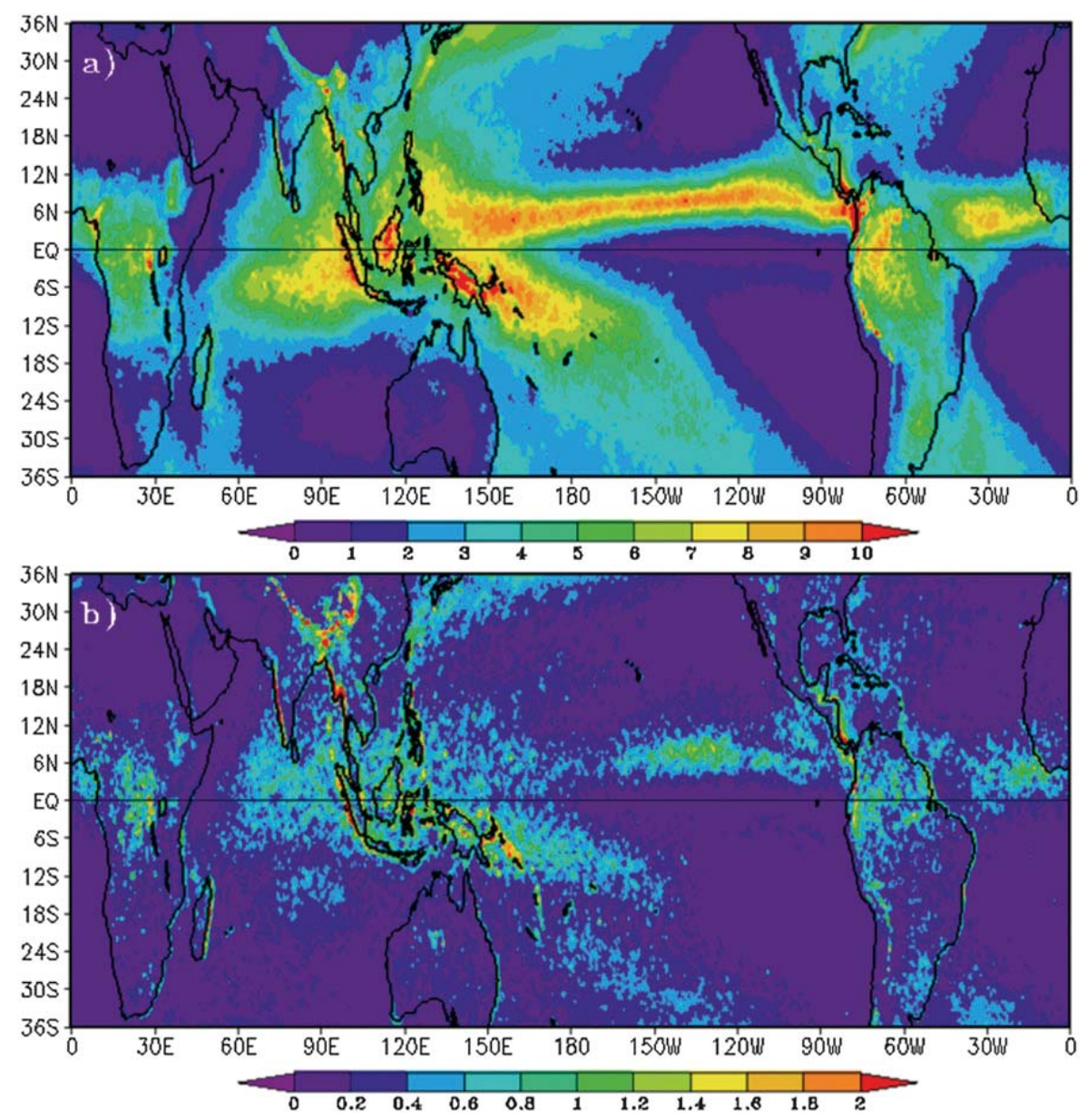

FIG. 1. (a) Climatology $\left(\mathrm{mm} \mathrm{day}^{-1}\right)$ and (b) std dev $\left(\mathrm{mm} \mathrm{day}^{-1}\right)$ among the TCC inputs for TRMM composite rainfall over 15 years (1998-2012).

Giving a measure of dispersion among the three products of the TCC at each point, the standard deviation $\sigma$ of the three estimates can then be used as a measure of confidence or an estimate of error. A similar approach has been used to estimate the uncertainty in the GPCP climatology (Adler et al. 2012), although that study was able to use a larger number of input estimates (up to eight) in most regions of the globe. The relationship between $\sigma$ and mean values of TCC in the tropics $\left(25^{\circ} \mathrm{S}-25^{\circ} \mathrm{N}\right)$, excluding higher latitudes in the TRMM area to avoid the problems related to the TMI product $2 \mathrm{~A} 12$ screening issues, is presented in Fig. 2. Although the comparisons have significant scatter, $\sigma$ generally increases with mean rainfall, as expected, with larger scatter and slightly higher $\sigma$ values over land than over ocean for the same mean rainfall. Coastal areas (Fig. 2c) have the highest $\sigma$ values in general, as do mountainous areas (see Fig. 1). Differences in $\sigma$ relations are also found between the western $\left(2.5^{\circ}\right.$ $\left.12.5^{\circ} \mathrm{N}, 130^{\circ}-160^{\circ} \mathrm{E}\right)$ and eastern Pacific $\left(5.0^{\circ}-15^{\circ} \mathrm{N}, 120^{\circ}-\right.$ $150^{\circ} \mathrm{W}$ ) (Figs. 2d,e), with the eastern Pacific having significantly higher $\sigma$ values, especially at high mean rain rates. This suggests that when ground validation is not always available for TCC, the standard deviation among TCC products is valuable for error estimation, at least in a relative sense and perhaps in terms of absolute values.

Over the ocean, the most pronounced feature is the $\sigma$ maximum (up to $1.5 \mathrm{~mm} \mathrm{day}^{-1}$ ) in the eastern Pacific Ocean rainfall maximum. Using a radiative transfer model, Shige et al. (2008) suggested that drop-size distributions (DSDs) in the eastern Pacific have stronger oceanic characteristics (i.e., more small-to-medium raindrops) than the initial DSD model of the PR algorithm, representative of the "data rich" western Pacific, leading to underestimation of rain by the PR. On the other hand, the TMI algorithm may overestimate the surface rainfall in the region due to the misrepresentation by the a priori database (C. Kummerow 2012, personal communication) used in the retrieval. The other noticeable areas of large dispersion values are found in regions along the northeast side of the SPCZ, which could also be a result of the differences in vertical structure and DSDs. Compared to TCC V6, the standard deviation in the subtropics, especially to the east 

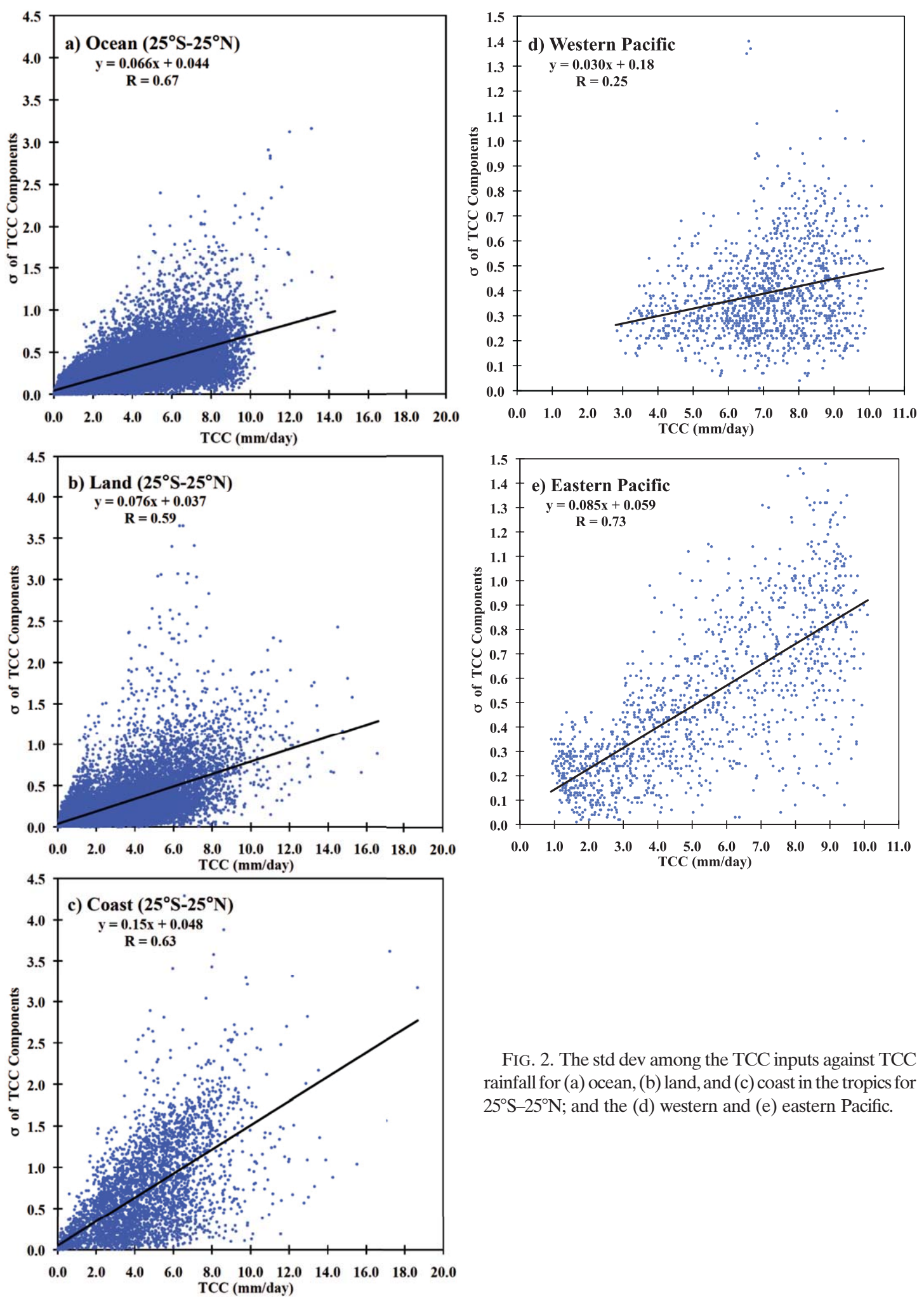

FIG. 2. The std dev among the TCC inputs against TCC rainfall for (a) ocean, (b) land, and (c) coast in the tropics for $25^{\circ} \mathrm{S}-25^{\circ} \mathrm{N}$; and the (d) western and (e) eastern Pacific.

of China and Japan, is reduced significantly thanks to the improvement of TMI algorithms in the subtropical region.

Over land, the standard deviations have finer spatialscale variations, usually due to orography, coastlines, or both. The mountainous regions (e.g., the Himalayan and

Andes chains as well as west coast of India with the Ghats Mountains) are areas with larger $\sigma$ values. This is not surprising because those areas are known to be problematic for passive microwave retrievals and even, to some extent, for the radar retrievals. It should be 


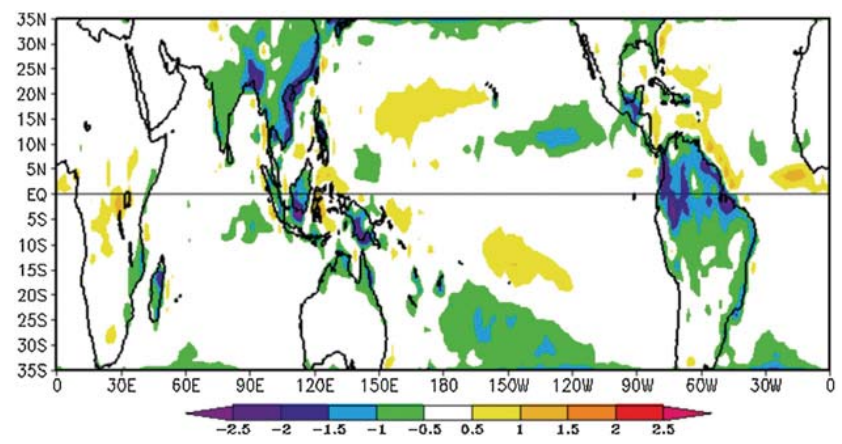

FIG. 3. Difference between TCC and GPCP rainfall ( $\mathrm{mm} \mathrm{day}^{-1}$ ) during 1998-2010.

noted that some of the largest dispersion values among TMI, PR, and the PR-TMI combined estimates are already excluded from the data presented in Fig. 3, based on the quality-control procedures. Coastal areas may exhibit large $\sigma$ values as the result of the algorithm transition from ocean to land. The passive microwave retrievals have a transition from pure ocean (multichannel physical retrieval) to scattering-based coastal ocean (TMI product 2A12 land algorithms applied to coastal waters). These uncertainty estimates for the TCC (standard deviation among input products) are generally lower in magnitude (over the ocean) than those from the similar approach used by Adler et al. (2012) for GPCP. This difference in error magnitude is mainly related to using three products (all from the same satellite and not completely independent) for the TCC in this paper and using eight products for the similar exercise for GPCP (over tropical oceans), including the three TRMM products. This emphasizes that the utility of this form of error estimate may be more in examining relative variation rates than absolute values. Over land the differences in error estimates are also due to gauges being used in GPCP, and not in this version of TCC.

\section{Evaluation and validation}

To evaluate and validate the TCC rainfall analysis and place this climatology into the context of other highly used datasets, we will perform a series of TCC comparisons with other satellite- and ground-based rainfall estimates.

\section{a. Comparison of the TCC with GPCP}

The Global Precipitation Climatology Project monthly rainfall product (Adler et al. 2003; Huffman et al. 2009) is an analysis on a $2.5^{\circ}$ global grid based on precipitation estimates from low-orbit microwave data over land and ocean with sampling enhanced with geostationary infrared data and utilizing a high-quality gauge-based analysis (Schneider et al. 2011). The GPCP monthly analysis is a widely used, community-based analysis
TABLE 1. Mean rainfall over 15 years (1998-2012; $\mathrm{mm} \mathrm{day}^{-1}$ ) from TRMM products, TCC, and GPCP.

\begin{tabular}{|c|c|c|c|}
\hline & Total & Ocean & Land \\
\hline \multicolumn{4}{|l|}{$22^{\circ}-35^{\circ} \mathrm{N} / \mathrm{S}$} \\
\hline TMI product $2 \mathrm{~A} 12$ & 1.98 & 2.22 & 1.42 \\
\hline PR product $2 \mathrm{~A} 25-\mathrm{NS}$ & 1.91 & 2.10 & 1.48 \\
\hline TM-PR combined product $2 \mathrm{~B} 31$ & 1.87 & 2.03 & 1.51 \\
\hline TCC & 1.90 & 2.12 & 1.42 \\
\hline GPCP & 2.11 & 2.36 & 1.61 \\
\hline \multicolumn{4}{|l|}{$10^{\circ}-22.5^{\circ} \mathrm{N} / \mathrm{S}$} \\
\hline TMI product $2 \mathrm{~A} 12$ & 2.28 & 2.33 & 2.14 \\
\hline $\mathrm{PR}$ product $2 \mathrm{~A} 25-\mathrm{NS}$ & 2.36 & 2.39 & 2.26 \\
\hline TM-PR combined product $2 \mathrm{~B} 31$ & 2.44 & 2.49 & 2.30 \\
\hline TCC & 2.36 & 2.40 & 2.24 \\
\hline GPCP & 2.44 & 2.40 & 2.55 \\
\hline \multicolumn{4}{|l|}{$10^{\circ} \mathrm{S}-10^{\circ} \mathrm{N}$} \\
\hline TMI product $2 \mathrm{~A} 12$ & 4.11 & 3.98 & 4.52 \\
\hline PR product $2 \mathrm{~A} 25-\mathrm{NS}$ & 4.46 & 4.30 & 4.96 \\
\hline TM-PR combined product $2 \mathrm{~B} 31$ & 4.63 & 4.54 & 4.93 \\
\hline TCC & 4.40 & 4.28 & 4.79 \\
\hline GPCP & 4.52 & 4.27 & 5.25 \\
\hline
\end{tabular}

and can be considered a standard to which new estimates can be compared. For comparison with the newly released GPCP, version 2.2 , the TCC with a $0.5^{\circ}$ resolution is averaged to match the resolution of GPCP at $2.5^{\circ}$.

Table 1 presents total, ocean, and land tropical rainfall estimates of the TCC over selected latitude bands, along with values for the input products and the GPCP values. Figure 3 presents a map of TCC - GPCP differences. It should be kept in mind that the GPCP contains gauge information over land, while the new TCC presented here is purely from the TRMM satellite retrievals. In the deep tropics $\left(10^{\circ} \mathrm{S}-10^{\circ} \mathrm{N}\right)$, the annual total, ocean, and land rain of TCC values are 4.4, 4.3, and $4.8 \mathrm{~mm}_{\text {day }}{ }^{-1}$, respectively. The corresponding GPCP values are 4.5, 4.3 , and $5.2 \mathrm{~mm} \mathrm{day}^{-1}$, respectively. The comparison indicates that, over the ocean, the GPCP and TCC estimates (both satellite-only estimates) are nearly identical (both $4.3 \mathrm{~mm} \mathrm{day}^{-1}$ ). Over land the TCC is lower than GPCP in the deep tropics by about $9 \%$, reflecting the effect of inclusion of the gauges in GPCP. Comparisons with gauge climatological values will be discussed in the next section. The values from the three components of the TCC have moderate dispersion numbers over ocean $(\sigma /$ mean $=\sim 5.4 \%)$ and smaller dispersion numbers over land $(\sigma /$ mean $=\sim 4.2 \%)$ in this zone.

Outside the deep tropics, in the latitude band of $10^{\circ}-$ $22.5^{\circ} \mathrm{N}$ and $\mathrm{S}(\mathrm{N} / \mathrm{S})$, over ocean the difference between TCC and GPCP is still essentially zero, but the difference over land increases somewhat, with the TCC being less than GPCP. Farther poleward, in the subtropics $\left(22.5^{\circ}-35^{\circ} \mathrm{N} / \mathrm{S}\right) \mathrm{TCC}$ is less than GPCP over water by about $10 \%$. The small dispersion $(\sigma /$ mean $=\sim 3.7 \%)$ 

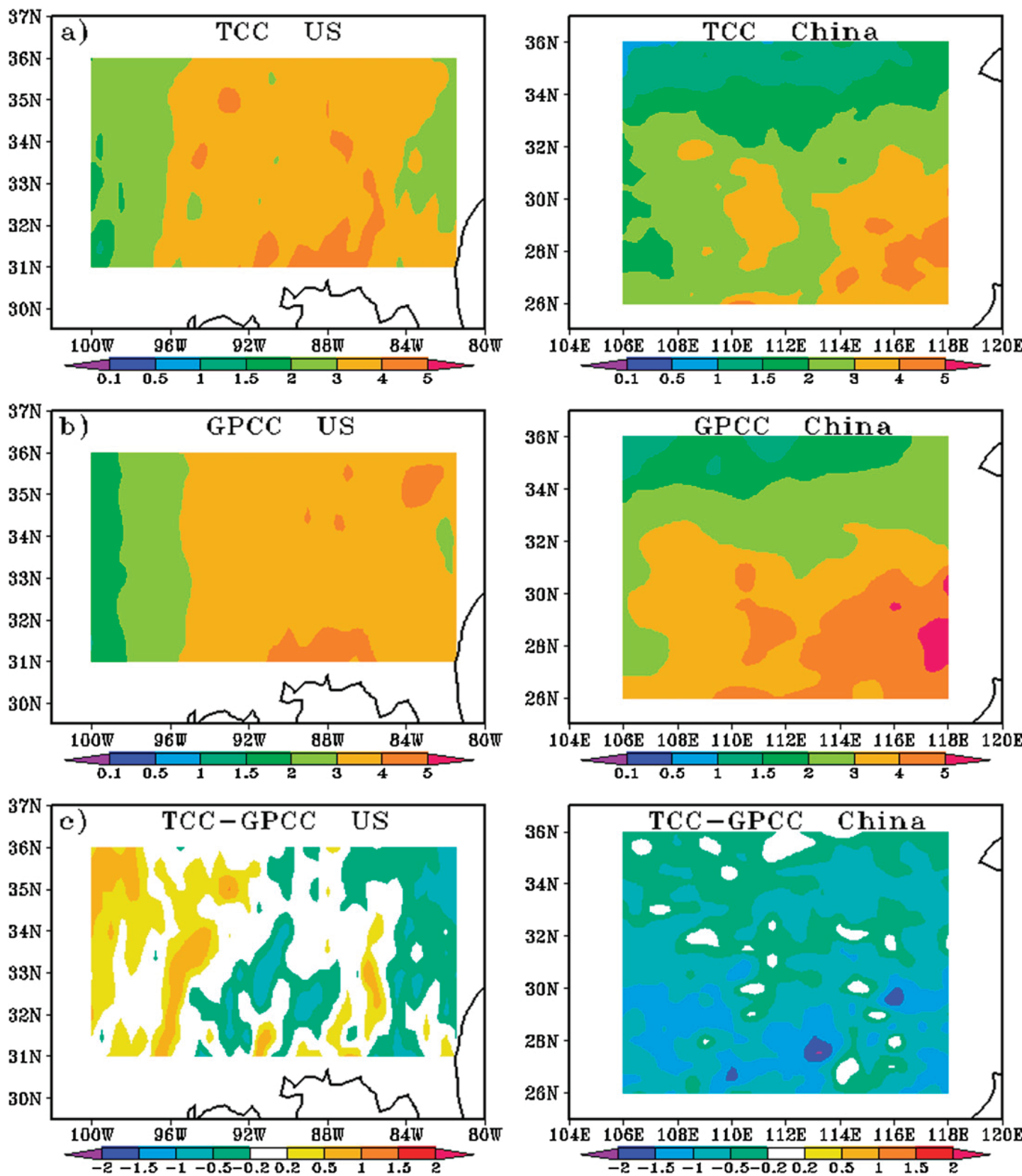

FIG. 4. Rainfall climatology over 13 years (1998-2010; $\mathrm{mm} \mathrm{day}^{-1}$ ) in (left) the southeastern United States and (right) eastern China: (a) TCC, (b) GPCC gauge analysis, and (c) TCC - GPCC.

here over the ocean should increase our confidence in the TRMM composite estimate, so that it is possible that the GPCP estimate is high. However, the current TMI retrieval (Kummerow et al. 2001) is based on vertical profiles of hydrometeors provided by a cloud model in the deep tropics and the TRMM PR, which somewhat lacks sensitivity to light rain. This could result in a larger underestimation of precipitation in middle latitudes, with more light rain occurring there than in the deep tropics. This underestimation could affect both the passive and active microwave retrievals. The pattern of differences over ocean in Fig. 3 indicates that the
TCC - GPCP difference is variable, with the main negative values at higher latitudes in the precipitation maxima and in the eastern Pacific along the northern edge of the ITCZ. Again, these are areas where light rain is more prevalent. The upcoming Global Precipitation Measuring (GPM) mission will help to investigate these areas, especially using the two-frequency radar, which will help with lighter rain and for possible drop-size retrievals.

The comparison made here among the different input products and between TCC and GPCP does not imply that one product or estimate is more correct than another. The TCC hopefully takes advantage of the various 

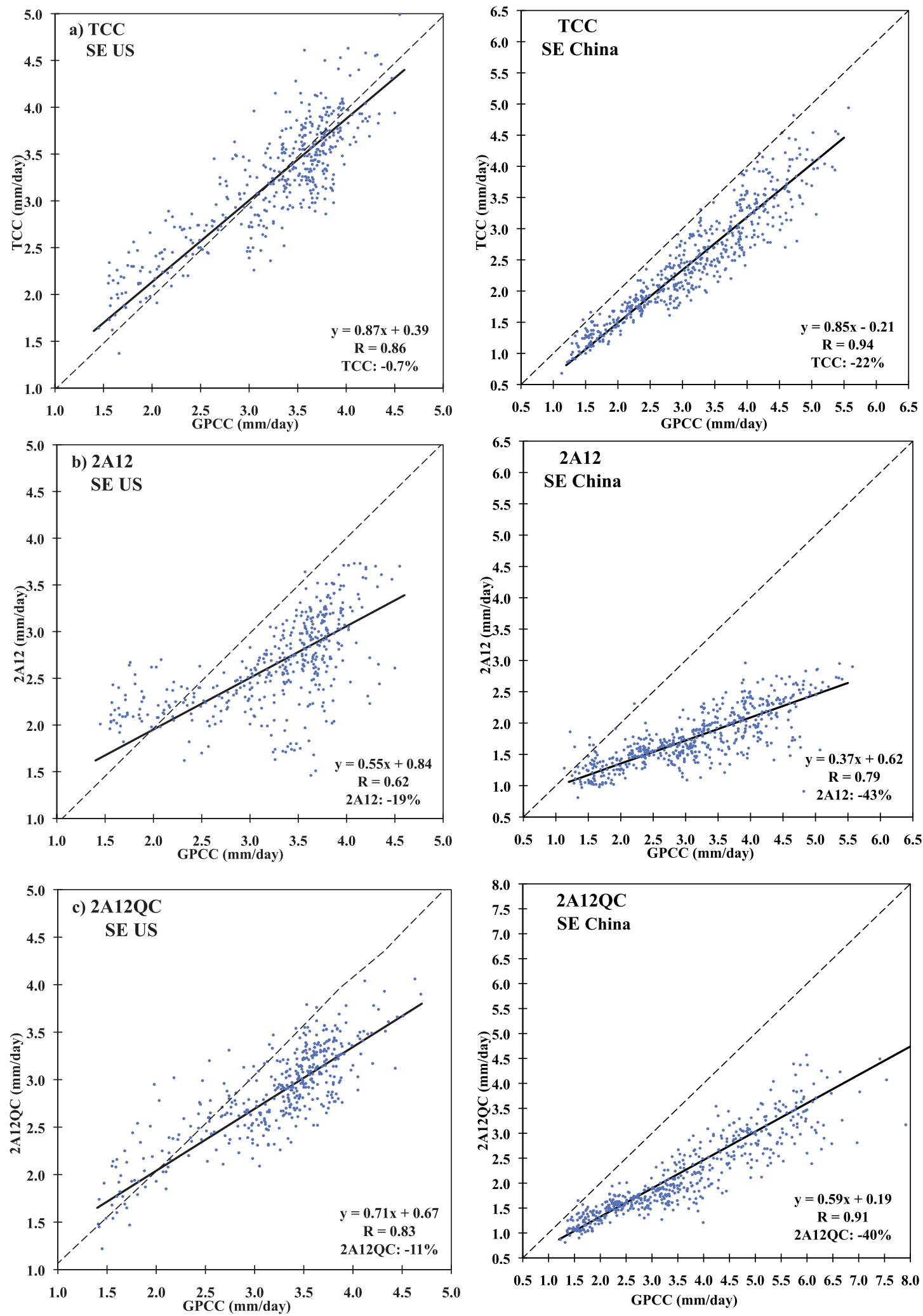

FIG. 5. Scatterplots of rainfall climatology over 13 years $\left(1998-2010 ; \mathrm{mm} \mathrm{day}^{-1}\right)$ in (left) the southeastern United States and (right) eastern China: GPCC gauge analysis and (a) TCC, (b) TMI product 2A12, (c) quality-controlled TMI product 2A12QC, (d) PR product 2A25, and (e) TM-PR combined product 2B31. 

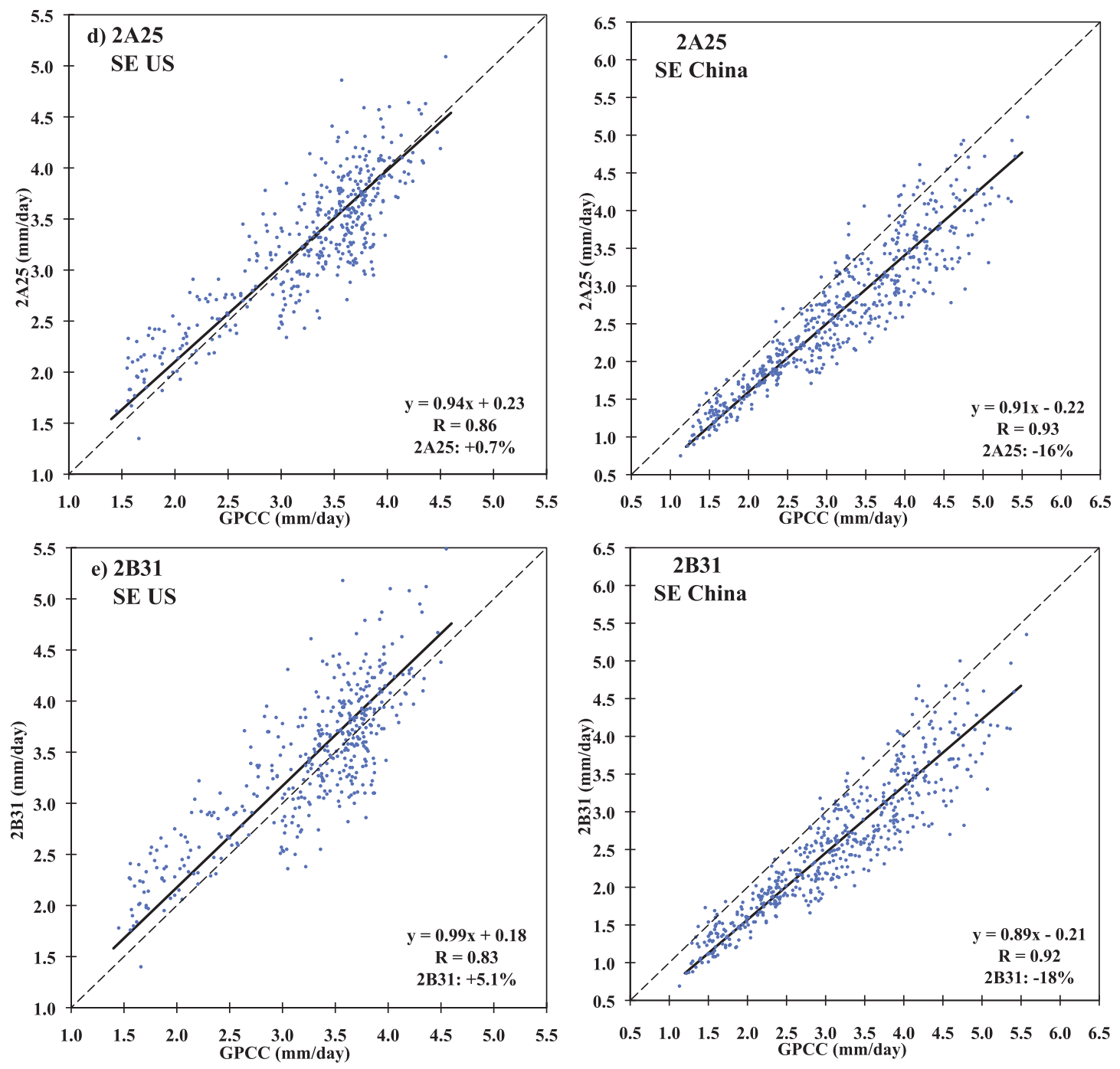

FIG. 5. (Continued)

TRMM-based estimates to provide an improved climatological product for surface rainfall, and the comparison with GPCP provides a link to a long-term standard used by many investigators. A key point, however, is that the TRMM estimates as a composite confirm the GPCP mean value in the core of the tropics over ocean $\left(\sim 25^{\circ} \mathrm{N}-\right.$ $25^{\circ} \mathrm{S}$ ). In a separate, recent analysis, Behrangi et al. (2012) used TRMM PR results (not adjusted for orbit boost) and CloudSat radar data to estimate tropical rainfall from $35^{\circ} \mathrm{N}$ to $35^{\circ} \mathrm{S}$ and arrived at a value for a 3 -yr period very close to the TCC and GPCP values.

\section{b. Comparison of the TCC with gauge-based analysis over land}

The Global Precipitation Climatology Centre provides analyses of the global land surface precipitation based on the rain gauge data from the national meteorological services worldwide. The GPCC gauge-based analysis is constructed by interpolating the quality-controlled data from over 8000 stations using the SPHEREMAP method (Willmott et al. 1985). Currently, the GPCC full data reanalysis (version 5) monthly gridded rainfall analysis over global land is available at $0.5^{\circ}$ resolution from 1901 to 2010. The same analysis is used in the GPCP monthly analysis and in the TMPA multisatellite product.

To evaluate the new TCC analysis over land, we have compared the 13-yr (1998-2010) TCC surface rainfall with the GPCC gauge-based analysis in the southeastern United States $\left(31^{\circ}-36^{\circ} \mathrm{N}, 82^{\circ}-100^{\circ} \mathrm{W}\right)$ and eastern China $\left(26^{\circ}-36^{\circ} \mathrm{N}, 106^{\circ}-118^{\circ} \mathrm{E}\right)$ (Fig. 4). The regions are chosen for comparison because they have dense rain gauge networks and provide good quality-controlled rainfall data in the TRMM domain. The gauge analysis used here is not adjusted for wind loss, which means that if such an adjustment were applied, the gauge-based analysis would have larger mean values. Overall, the rainfall pattern and the magnitude of the TCC estimates have a good agreement with the GPCC analysis. The 
comparison based on scatterplots (Fig. 5) found that the TCC has a very small bias relative to the GPCC in the southeastern United States, but an underestimation of about $22 \%$ in eastern China (Fig. 5a). To further examine the TCC rainfall estimates, all four TRMM products used in this study are compared with the GPCC analysis as well (Figs. 5b-e). The TMI product 2A12, which is not fully used in the TCC land analysis, exhibits the most scatter and the lowest correlation coefficient (0.62 and 0.79 ) with the GPCC analysis. Unfortunately, this seems to be an issue with the TMI passive microwave (PMW) algorithm over land (in TRMM V7) underestimating in general. This analysis confirms that further improvements of TMI land algorithms are required to reduce the uncertainties in these retrievals. For the annual climatology in the figure, once grid locations/months where TMI product $2 \mathrm{~A} 12$ is deemed an outlier are removed through the quality-control (QC) process, the quality-controlled TMI product $2 \mathrm{~A} 12 \mathrm{QC}$ rainfall data have much higher correlation coefficients ( 0.83 and 0.91 ) when compared with the GPCC analysis. However, this is at the expense of eliminating the use of this rainfall estimate at $16 \%$ of the grids over land. Also, because the removal of TMI product 2A12 data in China occurs mostly during the winter months with less rainfall, the mean of the matched remaining month-of-the-year rainfall increases in the comparison between TMI product 2A12QC and GPCC (Fig. 5c). The PR product 2A25 gives very close estimates to the GPCC analysis in the southeastern United States, but shows underestimation $(16 \%)$ in eastern China. The correlation coefficient of PR in these two regions is high at 0.86 and 0.93 , respectively. The TMI-PR combined product $2 \mathrm{~B} 31$ also features high correlation coefficients of 0.83 and 0.92 , although with the same pattern of bias as the radar-only algorithm over the United States and China.

Although the comparisons between TCC and GPCC gauges shown here are for two regions only, they are similar to a broader comparison with GPCC data over the global tropics (not shown). The results confirm that the differences between satellite-based precipitation estimates including TRMM to gauges may have substantial spatial variations (Tian et al. 2009). In addition, our comparison reveals that the differences between TRMM products and gauges also have significant seasonal variations (not shown). For instance, TMI rainfall estimates produce more artifacts in winter at elevated regions due to TMI's problematic rain/no rain screening. And both TMI and PR have more underestimation in winter partially because of the more-frequent shallow and/or light rain.

There still may be bias and other issues with the gauge networks. For example, it is not clear why there is a difference between the United States and China for similar climatic zones; perhaps the gauge measurements themselves have different biases regionally. However, it is clear that the radar-based algorithms are superior to the passive microwave retrievals over land, in terms of bias and correlation and in terms of artifacts (TMI product 2A12 results improve significantly when suspicious grids are eliminated). Passive microwave algorithms must improve over land to be continuously used in assessing mean values of precipitation and even variations.

\section{c. Comparison of the TCC with atoll data}

The Comprehensive Pacific Rainfall Database, with data collected from hundreds of Pacific island and atoll stations $\left(45^{\circ} \mathrm{S}-28^{\circ} \mathrm{N}, 90^{\circ} \mathrm{W}-120^{\circ} \mathrm{E}\right)$, is the most extensive Pacific rain gauge database (Greene et al. 2008). In this study, only atoll rainfall data from PACRAIN, hopefully representing open-ocean rainfall, are used for comparison with TCC. Throughout the TRMM era and within the TRMM domain, there are total of 36 atoll stations with at least 1 year of data recorded. The comparison is done on a climatological basis; that is, the mean values of the monthly atoll rainfall amount from 1998 to 2010 are compared with the rainfall estimates in the corresponding $0.5^{\circ}$ grid by TCC in the months when atoll data are available.

The scatterplots of TCC and its component rainfall estimates are shown in Fig. 6 in comparison with atoll gauge data. Overall, the TCC estimates are lower than the atoll data by about $16 \%$, with high correlation values. This suggests reasonable estimates from TCC, comparable to the mean values from GPCP, which are also lower than the atoll data by about $16 \%$ (e.g., Adler et al. 2003). It is possible that the satellite technique is underestimating the precipitation, but there is also the possibility that the atoll gauges are not completely representative of the open-ocean precipitation. Recently, two studies using TRMM PR data to try to understand the effects of small islands/ atolls on precipitation have mixed results. Sobel et al. (2011) indicate that the influence is negligibly small, while M. Hirose (2013, personal communication) concluded that even for flat, small islands, the rainfall enhancement by the island or atoll is evident, especially when the scale of the precipitating system is small. This issue requires further attention in our attempts to derive an accurate ocean rainfall absolute magnitude. It is also noticed that, percentagewise, the differences between TCC and the atoll data are similar from low to high rain-rate regions. Similar to the comparison over land discussed before, the results of this comparison are for the central and western Pacific Ocean, the only region where the atoll stations are located. In addition, all three TCC components over ocean have similar and high correlation coefficients with the atoll data, which also result in much smaller dispersion values among them than over land. 

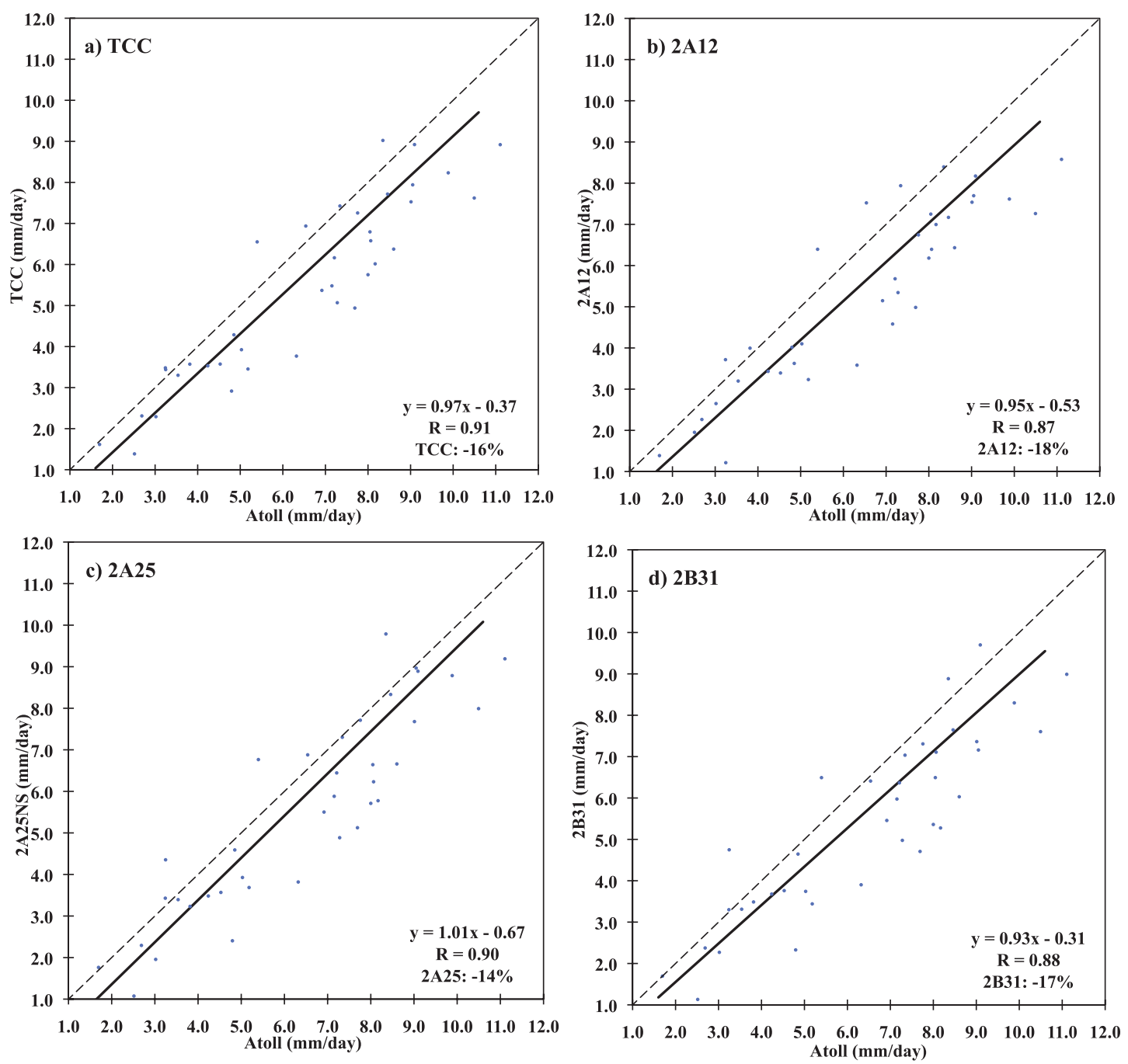

FIG. 6. Scatterplots of 13-yr (1998-2010) rainfall climatology $\left(\mathrm{mm} \mathrm{day}^{-1}\right)$ from PACRAIN atoll data and (a) TCC, (b) 2A12, (c) 2A25, and (d) 2B31.

This result indicates that the passive microwave products over ocean may be as useful as the radar-based estimates for climatologies of surface rainfall, at least in this one part of the tropical ocean.

\section{Summary and future work}

An updated, 15-yr tropical surface rain climatology based on a selection of TRMM products, with the impact of the satellite boost taken into account, is presented. The data of the TCC and standard deviation of its inputs of annual and month-of-the-year values are available through the $\mathrm{Na}$ tional Aeronautics and Space Administration (NASA) Goddard Data and Information Service Center (DISC) online (at mirador.gsfc.nasa.gov).

The main purpose of the calculated TCC rainfall dataset is to provide a summary of the rainfall measurements by the TRMM satellite and estimates of the mean values or climatology from this satellite program. For the purpose of evaluation and validation, the TCC estimates are compared with other satellite-based and groundbased rainfall estimates including GPCP, GPCC gauge analysis, and PACRAIN atoll data. In general, the comparisons indicate that the TCC provides reasonable estimates within the margin of bias error for both the satellite estimates and the surface gauge data. The TCC provides an alternate climatology to the often-used GPCP over the tropics. TRMM data, perhaps in a form close to the TCC, will be included at some point into GPCP. For now the TCC and its accompanying error estimates can be used for general assessment of global models and for water budget studies.

In the tropics, TCC rainfall is essentially the same as GPCP over ocean, but about 9\%-12\% lower than GPCP over land, reflecting the effect of inclusion of the gauges in GPCP. In the subtropics, the difference between TCC and 
GPCP is quite similar over both ocean and land with a magnitude from $\sim 10 \%$ to $\sim 12 \%$. Over the southeastern United States and southeastern China, the TCC estimates exhibit very good agreement with GPCC gauge analysis in regard to the rainfall pattern. However, the detailed comparison indicates that the TCC has a very small bias relative to the GPCC in the southeastern United States, but a considerable underestimation in eastern China. Further analysis reveals that the radar-based algorithms are superior to the passive microwave retrievals over land, in terms of bias and correlation. Over the open ocean in the central-to-western Pacific, the TCC is about $16 \%$ lower than the PACRAIN atoll data, similar to the bias of the GPCP estimates compared to the same dataset. All three TCC components have similar mean values and high correlation coefficients with the atoll data, suggesting that the passive microwave products over ocean may be as useful as the radar-based estimates over tropical oceans. Additional work is required to understand the relationships between the atoll rain gauge values and the satellite estimates and whether the difference in magnitude is a bias error in the satellite estimates or a representative issue with the atoll gauges.

It is concluded that the calculated TCC dataset is valuable as a summary of TRMM mean value results and may have broad applications. The TCC should be useful as a convenient, high-quality TRMM estimate to the user community interested in climate monitoring, climate variability studies, water budget analysis, and model initialization and validation, as well as comparison with other non-TRMM rainfall analysis.

Acknowledgments. This research was carried out with the support of NASA's Precipitation Measurement Missions (PMM) program, headed by Dr. Ramesh Kakar of NASA Headquarters. The constructive suggestions by two anonymous reviewers also improved the presentation of this study.

\section{REFERENCES}

Adler, R. F., and Coauthors, 2003: The Version-2 Global Precipitation Climatology Project (GPCP) monthly precipitation analysis (1979-present). J. Hydrometeor., 4, 1147-1167.

—, J.-J. Wang, G. Gu, and G. J. Huffman, 2009: A ten-year tropical rainfall climatology based on a composite of TRMM products. J. Meteor. Soc. Japan, 87A, 281-293.

—, G. Gu, and G. Huffman, 2012: Estimating climatological bias errors for the Global Precipitation Climatology Project (GPCP). J. Appl. Meteor. Climatol., 51, 84-99.

Behrangi, A., M. Lebsock, S. Wong, and B. Lambrigtsen, 2012: On the quantification of oceanic rainfall using spaceborne sensors. J. Geophys. Res., 117, D20105, doi:10.1029/2012JD017979.

Berg, W., T. L'Ecuyer, and C. Kummerow, 2006: Rainfall climate regimes: The relationship of regional TRMM rainfall biases to the environment. J. Appl. Meteor. Climatol., 45, 434-454.
Gopalan, K., N.-Y. Wang, R. Ferraro, and C. Liu, 2010: Status of the TRMM 2A12 land precipitation algorithm. J. Atmos. Oceanic Technol., 27, 1343-1354.

Greene, J. S., M. Klatt, M. Morrissey, and S. Postawko, 2008: The Comprehensive Pacific Rainfall Database. J. Atmos. Oceanic Technol., 25, 71-82.

Haddad, Z. S., E. A. Smith, C. D. Kummerow, T. Iguchi, M. R. Farrar, S. L. Durden, M. Alves, and W. S. Olson, 1997: The TRMM "day-1" radar/radiometer combined rain-profiling algorithm. J. Meteor. Soc. Japan, 75, 799-809.

Huffman, G. J., and Coauthors, 2007: The TRMM Multisatellite Precipitation Analysis: Quasi-global, multi-year, combinedsensor precipitation estimates at fine scale. J. Hydrometeor., 8, 38-55.

_ R. F. Adler, D. T. Bolvin, and G. Gu, 2009: Improving the global precipitation record: GPCP version 2.1. Geophys. Res. Lett., 36, L17808, doi:10.1029/2009GL040000.

Iguchi, T., and R. Meneghini, 1994: Intercomparison of singlefrequency methods for retrieving a vertical rain profile from airborne or space borne radar data. J. Atmos. Oceanic Technol., 11, 1507-1516.

Kummerow, C., and Coauthors, 2000: The status of the Tropical Rainfall Measuring Mission (TRMM) after two years in orbit. J. Appl. Meteor., 39, 1965-1982.

— , and Coauthors, 2001: The evolution of the Goddard profiling algorithm (GPROF) for rainfall estimation from passive microwave sensors. J. Appl. Meteor., 40, 1801-1820.

Masunaga, H., and C. Kummerow, 2005: Combined radar and radiometer analysis of precipitation profiles for a parametric retrieval algorithm. J. Atmos. Oceanic Technol., 22, 909-929.

— T. Iguchi, R. Oki, and M. Kachi, 2002: Comparison of rainfall products derived from TRMM Microwave Imager and Precipitation Radar. J. Appl. Meteor., 41, 849-862.

Schneider, U., A. Becker, P. Finger, A. Meyer-Christoffer, B. Rudolf, and M. Ziese, 2011: GPCC full data reanalysis version 6.0 at $0.5^{\circ}$ : Monthly land-surface precipitation from rain-gauges built on GTS-based and historic data. Deutscher Wetterdienst, doi:10.5676/DWD_GPCC/FD_M_V6_050.

Shige, S., T. Watanabe, H. Sasaki, T. Kubota, S. Kida, and K. Okamoto, 2008: Validation of western and eastern Pacific rainfall estimates from the TRMM PR using a radiative transfer model. J. Geophys. Res., 113, D15116, doi:10.1029/2007JD009002.

Shimizu, S., R. Oki, T. Tagawa, T. Iguchi, and M. Hirose, 2009: Evaluation of the effects of the orbit boost of the TRMM satellite on PR rain estimates. J. Meteor. Soc. Japan, 87A, 83-92.

Sobel, A. H., C. D. Burleyson, and S. E. Yuter, 2011: Rain on small tropical islands. J. Geophys. Res., 116, D08102, doi:10.1029/ 2010JD014695; Corrigendum, 118, 2301-2302, doi:10.1002/ jgrd.50205.

Tian, Y., and Coauthors, 2009: Component analysis of errors in satellite-based precipitation estimates. J. Geophys. Res., 114, D24101, doi:10.1029/2009JD011949.

Wang, J.-J., R. F. Adler, and G. Gu, 2008: Tropical rainfall-surface temperature relations using TRMM precipitation data. J. Geophys. Res., 113, D18115, doi:10.1029/2007JD009540.

Wang, N.-Y., C. Liu, R. Ferraro, D. Wolff, E. Zipser, and C. Kummerow, 2009: TRMM2A12 land precipitation productStatus and future plans. J. Meteor. Soc. Japan, 87A, 237-253.

Willmott, C. J., C. M. Rowe, and W. D. Philpot, 1985: Small-scale climate maps: A sensitivity analysis of some common assumptions associated with grid-point interpolation and contouring. Amer. Cartogr., 12, 5-16. 